\title{
PAUSE AS A PHRASE DEMARCATOR FOR SPEECH AND LANGUAGE PROCESSING
}

\author{
JUNKO HOSAKA MARK SFLIGMAN HARALD SINGER
}

ATR Interpreting Telephony Research Laboratories

Hikaridai 2-2, Seika-cho, Soraku-gun, Kyoto 619-02, Japan

\begin{abstract}
In spontaneous speech understanding a sophisticated integration of speech recognition and language processing is especially crucial. However, the two modules are traditionally designed independently, with independent linguistic rules. In Japanese speech recognition the bunsctsu phrase is the basic processing unit and in language processing the sentence is the basic mit. This difference has macle it impractical to use a unique set of linguistic rules for both types of processing. Further, spontaneous speech contains unexpected utterances other than wellformed sentences, while linguistic rules for both speech and language processing expect well-formed sentences. They therefore fail to process everyday spoken language. To bridge the gap botween speech and language processing, we propose that pauses be treated as phrase demarcators and that the interpansal phrase be the basic common processing unit. And to treat the linguistic phenomena of spoken language properly, we survey relevant features in spontaneous spech data. We then exanine the effect of integrating pausal and spontaneous speech phenomena into syutactic rules for specch recognition, using 118 sentences. Our experiments show that incorporating pausal phenomena as purely syntactic constraints degrades recognition accuracy considerably, while the additional degralation is minor if some further spontaneons spech features are also incorporated.
\end{abstract}

\section{INTRODUCTION}

A spontianeous speech understanding system accepts naturally spoken input and understands its meaning. In such a system, spcech processing and language processing must be integrated in a sophisticated mamner. Ilowever, the integration is not straightforward, as the two are studied independently and have different processing units. Moreover, spontancous specch contains unexpected phenomcna, such as hesitiations, corrections and fragmentary expressions, which thus far have not been treated in linguistic rules.

The most significant concern in speech processing is raising the recognition accuracy. For that purpose, applying linguistic information, e.g. using stochastic models[1], syntactic rules[2], semantic information[3] and discourse plans[4], is most promising. In a recent Japanese specch translation system[5] bunsetsu-based syntactic constraints are successfully applied in the speech processing module[6] $]^{1}$. However, rules repre-

\footnotetext{
${ }^{1} A$ bunsetsu roughly corresponds to a phrase and is the next largest unit after the word. The number of words in a phrase ranges from 1 to 14 , and the mean number is abont $3[7]$.
}

senting the same constraints cannot be used directly in sentence-based language processing, where the primary concern is to understand sentence meaning. In speech recognition, a sequence of words forms a bun. setsu and a set of bunsetsus then forms a sentence. In language processing, on the other hand, where the sentence is the basic processing unit, treating the main verb and its complements is usually the core of processing. For the sentence kaigi ni moshikomi tai no desu ga, meaning 'I would like to apply for the conference,' the processing discrepancy is sketched in Figure 1:

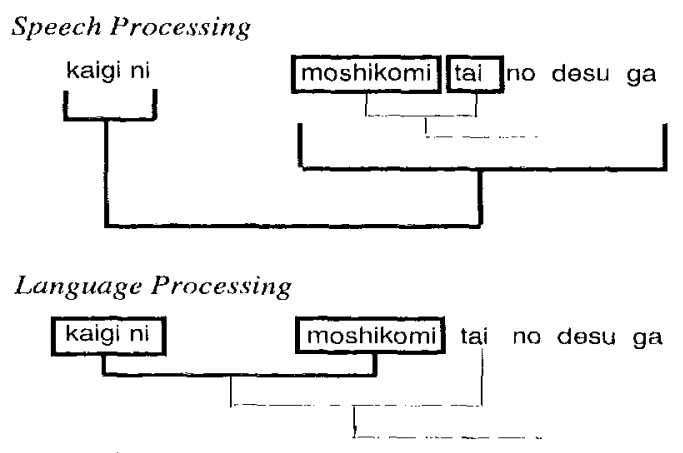

Figure 1: Structural Difference

Although linguistic rules for speech recognition always cope with uncertain phoneme hypotheses, they still expect well-formed speech input, and this is even more true of linguistic rules in language processing. In spontancolss speech, however, there are hesitations, corrections and incomplete utterances which are not treated in the conventional framework.

In addressing spontaneous speech understanding, two main problems must be solved: the absence of common processing components as sketched in F'igure 1, and our insufficient knowledge of spontaneous speech features. In this paper, we propose the pause as a phrase demarcator and the interpausal phrase as the basic processing unit. A phrase is naturally demarcated with pauses in spoken language and an interpausal phrase often functions as a meaning unit [8][9]. In spontaneous specch understanding we must both accept naturally spoken input and understand its meaning. Use of the pause as a phrase demarcator is advantageous for both of these purposes. Further, we investigate several frequent spontaneous 
speech features using spontaneous speech data[10]. We then apply the study to speech recognition. We examine the effect of integrating into syntactic rules pausal phenomena and certain features of spoken languago, using 118 test sentences.

\section{ANALYSIS OF SPONTA- NEOUS DIALOGUES}

\subsection{Spontaneous Dialogue Data}

As sources of spontaneous data, we use four Japanese dialogues concerning directions from Kyoto station to either a conference center or a hotel, collected in the Environment for Multi-Modal Interaction[10]. Spcaker $\mathrm{A}$ is pre-trained to give the directions, mentioning possible transportation, location and so forth. 'T'wo subjects seeking directions, Speaker B and Spcaker $\mathrm{C}$, are given some keywords, such as the name and the date of the conference. 'They may use telephone connections only, or may use a multimodal setup with onscreen graphics and video as woll. Table 1 shows how many words are used in the dialogues studied:

Table 1: Words in the Corpora

\begin{tabular}{|l|r|r|}
\hline & Telephone & Multimedia \\
\hline Spcakers A,B & 536 & 714 \\
Speakers A,C & 1167 & 1124 \\
\hline Subtotal & 1703 & 1838 \\
\hline Total & \multicolumn{2}{|c|}{3541} \\
\hline
\end{tabular}

The corpora consists of 3541 words in total, and contains 440 different words. It has 403 turn-takings, and thus roughly 403 sentences.

In the multimedia setup, speakers use deictic expressions such as koko and kore meaning "here" and "this," respectively. The dialogues also lasted longer than those in the telephonc-only setup. However, wo did not find any further distinct differences between the two setups. We therefore analyse all of the dialogues in the same way.

For our study, transcripts of the spontancous dialogues have becn prepared, and these contain morphological tags and turn-taking information. Pause information within turns, i.e., breaths or silences longer than 400 miliseconds, is provided as well.

\subsection{Pause as a Phrase Demarcator}

In Table 2 we illustrate the adequacy of the interpausal phrase as a processing unit with a series of directions to Kyoto station's Karasumachou exit. The cntire explanation consists of three turns separated by short response syllables, such as hai, that do not overlap the explanation. That is, the speaker paused during these responses. We marked each turn with TURN at the end. As a primary demarcator we used pauses and turns. Thus either PAUSE or TURN appears in the second column. Further demarcator candidates such as the filled pauses anoo or eeto, the emphasis marker desune and the response syllable hai when overlapping the explanation appear in the third column as FILLED PAUSE, DESUNE and RESPONSE, respectively. $\Lambda$ rough translation follows each interpausal phrase:

Table 2: Phrase Demarcator

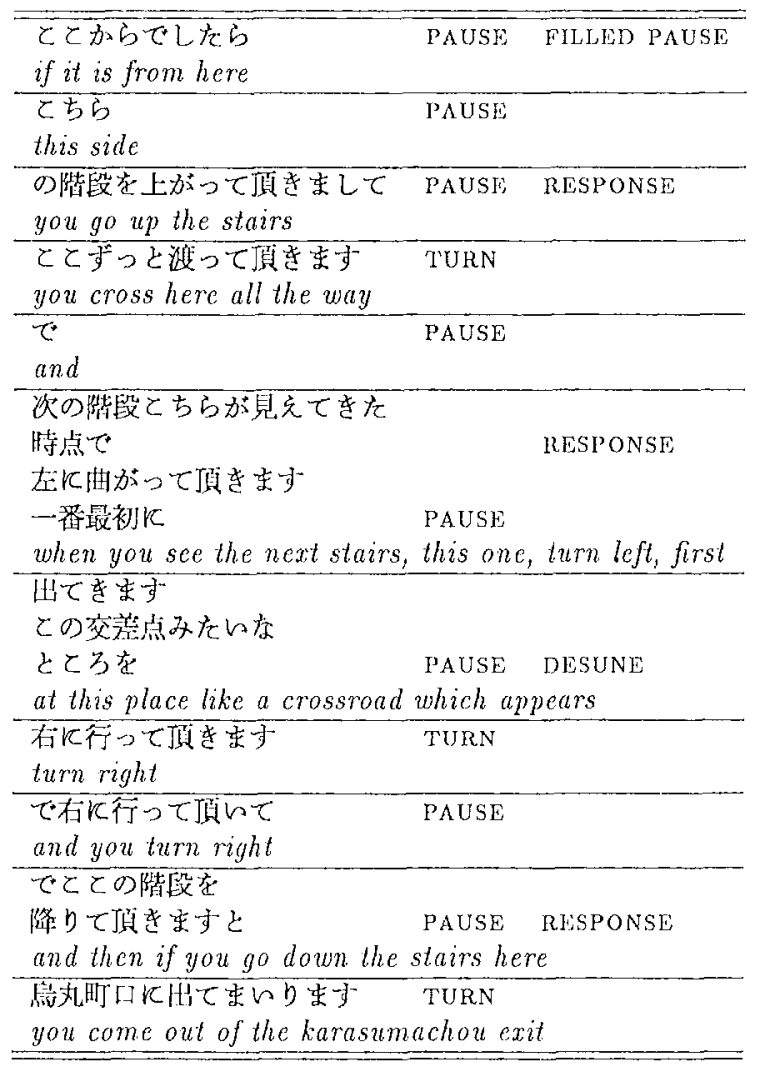

The length of the processing unit plays an important role in speech recognition. Table 2 shows that alternative demarcator candidates such as FILLED PAUSE and RESPONSF usually cooccur with pauses. In Table 2, for example, we find only one case where RESPONSE does not cooccur with a pause. Consequently, the segments within turns bounded by these alternative markers would not be much different from those bounded by pauses; in particular, they would not be much shorter or longer. Thus, at least where length is concerned, the combination of PAUSE and TURN seems appropriate and sufficient to mark out phrases. With respect to language processing, Table 2 shows that interpausal phrases are often adequate as translation units, which suggests that such phrases often function as meaning units.

Interpausal phrases typically end with a conjunctive postposition, such as ga or keredomo; a postpositional phrase; an interjection, such as hai or moshimoshi; the genitive postposition no for adnominals; 
an adnominal conjugation form; a coordinate conju gation forn; auxiliaries with sentence final conjughlion form; or a sentence final particle, such as kit or ne.

\subsection{Features of Spontancous Dia- logues}

We studied ten features of spontancons dialogues which are not considered in grammars for well-formed sentences $[6][11]$. 'Table 3 shows the features and their frequencies:

\begin{tabular}{|l|r|} 
Table 3: Feature and Oecurence \\
\hline Use of desune & 37 \\
Use of anoo & 35 \\
Fragmentary utterance & 26 \\
Use of ecto & 15 \\
lind of turn with a l'] & 7 \\
Postposition drop & 7 \\
Question withont ka & 5 \\
Jisfluency: soudesune & 5 \\
Apposition & 4 \\
Inversion & 3 \\
\hline
\end{tabular}

We expected a very high frequency of the filled pauses anoo and ecto functioning as discourse? managers[12]. Ilowever, Table 3 shows only a mockcst frequency. Phonological vastations such as allnoo and ano for anoo and ettoo and ectlo for ecto were not comnted. This maly be why the frequency of both expressions is unexpectedly low

Some fatures shown in Table 3 are liscussed in the exanule sets below. Features in focus are in bold type:

\section{Ex. 1}

sochira no desme noriba kara basu ga desume delemasu

there is a bus from that bus stop

The person giving directions often uses the expression desune. The use of desunc emphasizes the preceding utterance, typically the inmediately preceding minimal phrase. In lix. 1. the first use emphasizes sochira no and the second stresses basu ga.

We denote the person griving the directions as Speaker $A$ and the person secking the infornation as Speaker $B$ in lixamples 2, and 3.

\begin{tabular}{|c|c|}
\hline Ix. 2 & \\
\hline Speaker 13: & $\begin{array}{l}\text { keage no kita } \\
\text { north of keage }\end{array}$ \\
\hline Specaker A: & sou desu \\
\hline Speaker B: & $\begin{array}{l}\text { deguchi } \\
\text { exit }\end{array}$ \\
\hline Speater A: & $\begin{array}{l}\text { kitadeguchi desu ne } \\
\text { it's the nor th cxit, okay? }\end{array}$ \\
\hline
\end{tabular}

In Fx. 2 Speaker $B$ did not finish what he wanted to say, but spoaker $A$ understeod his intention and interrupted his utterance, which is therefore fragnenLary. Speaker 13 continued but before he conld finish Spoaker A finished for him. So Spealier B's utterance is again fragnent,ary.

$$
\begin{aligned}
& \text { Speaker A: futacki do } \\
& \text { after two stops } \\
& \text { Ex. } 3 \text { Speaker B: keage } \\
& \text { keage } \\
& \text { Speaker A: sou desu } \\
& \text { that's right }
\end{aligned}
$$

Speaker $A$ is giving directions but before he has conpleted his nttrance Speaker 13 interrupts with the station nane. Speaker $A$ did not contimue his first utterance and agreed with Speaker B. Speaker A's first nterance is a nominal phrase, which is never completed.

\section{APPLICATTON OF THE ANAIYSIS}

Tho examine the feasibility of integrating into syntactic rules both pausal phenomena and the foatures of spontannous speech studied in Section 2, we prepared three different sets of rules. In all three sets, rules have been explicitly modified to represent pansal phenonena. The first set pause contains only such modifications, while the other two sets add one additional spontancous feature each: rule set Emphasis permits use of the emphasis marker desune alter a nom phrase, while rule set Turn allows postpositional utterances at the end of a turn. Wo conducted pre. lininary specch recognition experiments with a parser which uses linguistic constraints written as a CFG.

\subsection{Linguistic Constraints}

To representi onr underlying linguistic constraints wo adapted existing syutactic rules developed for spech recognition[6]. Warlier experinents using bunselste. based speech input showed $70 \%$ sentence recognition acciaracy for the top candidate and $84 \%$ for the top 5 candiclates.

'The format for all of our syntactic rulcs is as follows:

$(\langle\operatorname{CAT} 1\rangle\langle-\rangle(\langle\operatorname{CAT} 2\rangle\langle\operatorname{CAT} 3\rangle))$

Nonterminals are surrounded by $\leftrightarrow$. The above rule indicates that CAT1 consists of CAT2 and CAT3 Wo denote the categories in interpansal phrase rules in lower-case and the categories in interpausal phrasebased sentence rules in upper-case.

In the rule set Pause we propared about 45 phrases that can end with a pause: postpositional phrases, conjunctive phrases, adnominal verbal phrases marked with a special conjugation form, 
phrases that end with a conjunctive postposition, adnominal phrases with the genitive postposition no, and coordinate verbal phrases. The first three rules are as follows:

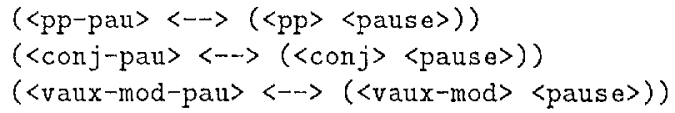

In the rule set Emphasis we prepared seven additional rules for treating the emphasis marker desune, represented as follows:

$(\langle$ pp-pau $\rangle\langle--\rangle(\langle$ pp $\rangle\langle$ emphasis $\rangle\langle$ pause $\rangle))$ $(<\mathrm{pp}-\mathrm{no}-\mathrm{pau}\rangle\langle-->$

$(\langle$ pp-no〉 $\langle$ emphasis $\rangle\langle$ pause $\rangle))$

Methods for combining interpausal phrases to obtain an overall utterance meaning require further study. At this stage we defined a sentence very loosely. It can be an interjection; an interjection followed by a combination of interpausal phrases; or simply a combination of interpausal phrases. 'To allow fragmentary utterances, in the rule set Turn, we also introduced a sentence consisting of a nominal phrase, which may contain adnominal phrases. Complete sentences in Turn are defined as follows:

$(\langle$ SSS $>\langle->(\langle$ INTERJ 1$\rangle))$

$(\langle$ SSS $\rangle\langle->(\langle$ INTERJ 1$\rangle\langle$ SS $\rangle))$

$(\langle\mathrm{SSS}\rangle\langle-\rangle(\langle\mathrm{SS}\rangle))$

$(\langle\mathrm{SSS}\rangle\langle\rightarrow\rangle(\langle\mathrm{M}-\mathrm{NN}\rangle))$

Table 4 shows the size and phoneme perplexity of the three sets of rules:

Table 4: Size and Perplexity

\begin{tabular}{|l|r|r|r|}
\hline & Pause & Emphasis & Turn \\
\hline Rules & 2326 & 2333 & 2327 \\
\hline Words & 751 & 752 & 751 \\
\hline Perplexity & 3.96 & 3.96 & 3.96 \\
\hline
\end{tabular}

A given phoneme string can belong to several categories. For instance, de can be a postposition or a copula conjugation form. The number of different phoneme strings is 503 for Pause and Turn, and 504 for Emphasis.

\subsection{Speech Recognition Experiment}

We conducted a speech recognition experiment with 118 test sentences concerning secretarial services for an international conference. A professional broadcaster uttered the sentences without any special constraints such as pause placement.

For our speech recognition parser, we used HMMLR[14], which is a combination of generalized IR parsing and Hidden Markov Models (HMM). The system predicts phonemes by using an LR parsing table and drives HMM phoneme verifiers to detect or verify them without any intervening structure such as a phoneme lattice. Ijinguistic rules for parsing can be written in CFG format.

As mentioned in section 3.1 , we explicitly defined rules that can end with pauses in linguistic constraints. According to the pause model, a pause can last from 1 to 150 frames, where a frame lasts 9 msec.

Examples (1) and (2) show the results of IIMMLR Japanese speech recognition ${ }^{2}$. (1) shows sample results of rule set Pause and (2) shows sample results of Turn. The phoneme strings which were actually pronounced are enclosed in I I:

(1) |kaiginoaNnaishowaomochidesuka| (Do you have a conference invitation?)

1: kaigi-no-P-aNnaisyo-o-omochi-desu-ka

2: kaigi-ni-P-aNnaisyo-o-omochi-desu-ka

3: kaigi-ga-p-aNnaisyo-o-omochi-desu-ka

$>$ 4: kaigi-no-P-aNnaisyo-wa-P-omochi-desu-ka

5: kaigi-ni-P-aNnaisyo-wa-p-omochi-desu-ka

(2) $\mid$ iie|(no)

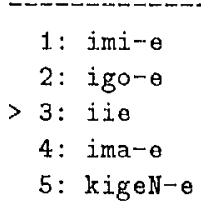

In the examples, the symbols $>,-, N$ and $P$ have special meaning: A correctly recognized phrase is marked with $>$. A word boundary is marked with A syllabic nasal is transcribed N. A pause is marked with $P$.

Example (1) shows typical recognition errors involving postpositions like no, ni, ga, and $o$, which often receive reduced pronunciation in natural speech. The surounding context may aggravate the problem. IIere, for instance, topic marker wa is erroneously recognized as object marker $o$ in the enviromment of preceding and subsequent phoneme $o$. The possible introduction of pauses at such junctures further complicates the recognition problem. Analysis deeper than CFG parsing will often be needed to filter unlikely candidates. Example (2) demonstrates the dangers of allowing postpositional phrases to end utterances. Here, all recognition candidates other than the third are inappropriate postpositional phrases. 'To recognize the unlikelihood of such candidates, we will need further controls, such as discourse management.

Our resulting sentence specch recognition accuracies are shown in Table 5. For instance, using rule set Pause, the correct candidate was the highest ranking candidate 50.0 percent of the time, Rank 1 , while the correct candidate was among the top 5 candidates 55.9 percent of the time, Rank 5 .

\footnotetext{
${ }^{2}$ The maximal amount of the whole beam width, called the global beam width, is set at 100 , and the maximal beam width of each branch, the local bean width, is 12 .
} 
Jable 5: Recognition Rate (\%)

\begin{tabular}{|r|r|r|r|}
\hline Rank & Pause & Emphas is & Turn \\
\hline 1 & 50.0 & 50.0 & 46.6 \\
2 & 54.2 & 54.2 & 53.4 \\
3 & 55.1 & 55.1 & 55.1 \\
4 & 55.9 & 55.9 & 55.9 \\
5 & 55.9 & 55.9 & 55.9 \\
\hline
\end{tabular}

With the underlying lingnistic rules for the threo rule sets, earlicr experiments had achieved $70 \%$ sentence speech recognition accuracy for specch input with explicil pauses at bunsetsu boundaries. Our best present results for spontaneous speech are much more modest: $50 \%$.

Jable 5 shows that the introduction of the emphasis marker desune dicl not affect processing: as seen in Table 4, rule set Emphasis has a slighuly higher perplexity than Pause, but we had exactly the samo results for the two. On the other hand, the perplexities of Pause and Turn are identical, but the treatinent of fragmentary utterances did decrease recognition accuracy.

\section{CONCLUSION}

To treat spontaneous speech understanding we havo two main problems: the absence of a common processing unit and insufficient knowledge of spontaneous speech features.

We have proposed pauses as phrase demarcators and interpausal phrases as common processing units to allow integration of spech recognition and language processing in the processing of spontancous speech understanding. We demonstrated the advantages of processing based on interpausal phrases using examples taken from spontianeous speech dialogues containing 3541 words. Using the same datel, we studied certain features of spoken language, such as filled pauses and fragmentary utterances. Based on the study, we propared three different CFG rule sets for preliminary specch recognition exporiments. In all three sets, rules have been explicitly modified to represent pausal phenomena. 'The first set contains only such modifications, while the other two sets add one additional spontancous feature each: use of the emphasis marker desune after a noun phrase or postpositional utterances at the end of a turn. For 118 sentences, sentence recognition accuracy for pausebased rules was considerably less than the accuracy obtained in earlier bunsetsu-based tests using mandatory pauses at bunsetsu bounclaries; but further loss of accuracy caused by incorporating the spontaneous features was minor.

We believe that the loss of speech recognition accuracy for sentences seen in our pause-based experiments is largely clue to the difficulties of combin ing interpausal phrase hypotheses. Our rules cur- rently combine interpausal phrases in a relatively unconstrained manner, using only weak syntactic constraints. Based on further study of the structures which precede and follow panses or filled pauses, wo hope to provide stronger syntactic constraints in the future.

\section{ACKNOWLEDGEMENTS}

We wish to thank I)r. Y. Yunazaki, President of A'TR-IT'I, 'I'. Morimoto, ITead of Department 4, and miny of our [T' colleagues for their generous support and encouragement.

\section{References}

[1] Lec, K.-F". and Hon, H.-W.(1988): "JargeVocabulary Speaker-Independent Continuous Speech Recognition Using IIMM," Proce of ICASSP-88, pp. 123-126.

[2] Ney, Il.(1987): "J)ynamic Programming Spcech Recognition Using a Context-Prec Grammar," Proc. of ICASSP-87, pp.69-72.

[3] Matsunaga, S., Sagayama, S., Ilomma, S. and Furui, S. (1990): " $\Lambda$ Continuous Speech Recognition System Based on a 'I'wo-Level Grammar Approach," Proc of ICASSP-90, pp.589-592.

[1] Yanaokit, T', and lida, H.(1990): "A Method to Predict the Next Utterance Using a Four-layered Plan Recognition Model," Proc. of FCAI-90, pp,726-731.

[5] Morimoto, 'T., 'Takezawa, 'T., Yato, F., el al.(1993): "AT'R's Spech Transhation System: ASURA," Proc. of Fin rospeech-93, Vol.2, pp. 1291-1294.

[6] Hosaka, J., Takezawa, 'T.(1992): "Construction of corpus-based syntactic rules for accurate speech recognition," proc. of COLING-92, pp, 806-812.

[7] Fhara, 'I., Ogura, K., Morimoto, T'. (1990): " $\Lambda \mathrm{TR}$ Dialogue 1)atabase," Proc of ICSJP-90, pp. 10931096.

[8] Foclor, J., Bever, T'(1965): "The psychological reality of linguistic segmonts," Jourual of Vorbal Learning and Bchavior, pp. 4:414-420.

[9] Sugito, M.(1988): "Pause and intonation in discourse," Nihongo to nilhongo kyouiku, Vol.2, pp.343. 363 (in Japanese).

[10] Joken-Kim, K., Yato, F., ct al.(1993): JiMMIATR environment for multi-modal interaction. T'T1T-0081, ATR.

[11] Hosaka, J.(1993): ^ Grammar for Japanese Generation in the TUG Framework, 'Technical Report T'R1-0346, AlR.

[12] Sadanobu, 'T., T'akubo, Y.(1993): "I'he Discourse Management Function of Fillers - a case of "ceto" and "ano(o)"-, Proc. of ISST)-93, pp.271-274.

[13] Husaka, J., 'lakezawa, 'l., Uratani, N.(1992): "Analyzing Postposition Drops in Spoken Japanese," Proc. of ICSLP-92, Vol.2, pp.1251-1254.

[14] Kiti, K., Kawabata, T., Saito, H. (1989): "HMM Continnous Specch Recogniton Using Predictive LR Parsing," Proc. of ICASSP-89, pp.703-706. 